\title{
Juan Bautista, Jesús, Pablo y la Comunidad de Qumrán
}

JUAN BAUTISTA, JESUS, PAUL and the Qumran Community

\section{Resumen}

Dr. Adolfo Roitman shrine@imj.org.il

Curador Rollos del Mar Muerto Santuario del Libro, Museo de Israel

Israel

El propósito de este texto es presentar, en forma muy resumida, la historia y las principales características de estos antiguos manuscritos, y destacar la importancia que tienen para comprender a tres personajes claves de la historia occidental. El mismo es una versión algo modificada de la conferencia pronunciada el día 12 de agosto de 2012 en el Museo de Arte Contemporáneo -MAC Parque Forestal.

Palabras clave: Qumrán - Rollos del Mar Muerto - Juan Bautista - Jesús - Pablo

\begin{abstract}
The purpose of this paper is to present, in a brief manner, the history and the main features of these ancient manuscripts and to highlight their importance in understanding three key figures in Western history. This paper is a somewhat modified version of the lecture delivered on August 12, 2012 at the Museum of Contemporary Art - MAC - Forest Park.
\end{abstract}

Keywords: Qumran - The Dead Sea Scrolls - John the Baptist - Jesus - Paul 


\section{El descubrimiento de los Rollos del Mar Muerto}

Los Rollos del Mar Muerto tienen su origen en una zona muy específica de Israel, el desierto de Judea, donde se encuentran el Mar Muerto y un lugar especialmente interesante llamado Qumrán, ubicado en su costa noroccidental, a 35 kilómetros al este de Jerusalén.

Probablemente Qumrán no es el nombre original sino que una denominación moderna, ya que recién aparece en textos de viajeros a partir del siglo XIX. Se cree que proviene del árabe Qamar que significa "luna".

En esta zona, una de las más secas del planeta, a fines del 1946 o a comienzos del verano de 1947, beduinos de la tribu de Ta'amra hallaron en jarrones de cerámica, en una de las cuevas que allí existen -después conocida como la cueva $\mathrm{N}^{0}$ 1- los primeros siete Rollos del Mar Muerto. Desde 1965 estos antiguos manuscritos están en exhibición en el Santuario del Libro de Jerusalén y son un ícono cultural del Estado Judío.

Las circunstancias del descubrimiento son importantes para entender el curso de las investigaciones posteriores y la manera de cómo los estudiosos habrían de entender el carácter de los manuscritos. Por ejemplo, la clasificación y nomenclatura de cada uno de los Rollos se efectúa anotando, junto con la letra Q, por Qumrán, el número de la cueva en que se encontró y el nombre del libro que contiene. Si hay más de una copia del libro, se ordenan en orden alfabético.

\section{El contenido de los manuscritos}

Dos de los siete primeros Rollos encontrados son copias de un mismo libro bíblico: el del gran profeta Isaías. Uno de ellos corresponde a la versión completa del libro, conteniendo los 66 capítulos de la versión tradicional. El texto es absolutamente legible y muy cercano al hebreo moderno, a pesar de ciertas diferencias en la grafía. La datación paleográfica, basada en la historia de la escritura de la lengua hebrea, lo fija aproximadamente entre los años 120 y 100 $\mathrm{AC}$, en la época del gobierno de los Macabeos. 
Para entender el significado excepcional que tuvo el descubrimiento de los Rollos del Mar Muerto, es necesario apreciar lo que se sabía anteriormente acerca de los escritos bíblicos. Hasta ese descubrimiento, todos los manuscritos conocidos de la Biblia Hebrea en su lengua original -la cual es el hebreo, a excepción de algunos pasajes en arameo- provenían de la época medieval; es decir, no había textos antiguos de la Biblia Hebrea.

Es el caso del llamado Códice de Alepo (nacido más bien en Tiberíades hacia el año 1000 EC), escrito por Schlomo Ben Buya'a y anotado y vocalizado por el gran sabio masoreta Aarón Ben Moshe Ben Asher. Originalmente el libro masorético completo tenía 490 páginas folio; actualmente tiene solo 295. Un fragmento de ese códice, que corresponde al libro bíblico de Éxodo capítulo 8, ha sido recuperado recientemente y puesto en exhibición en el Santuario del Libro. Otro ejemplo es el manuscrito medieval completo más antiguo de la Biblia Hebrea, el Códice de Leningrado, que está en la Biblioteca de San Petersburgo y que proviene del siglo XI EC.

A excepción de algunos manuscritos en hebreo, anteriores a los señalados (como el Codex Cairensis del siglo IX EC o fragmentos bíblicos hallados en la Genizah de El Cairo), los textos bíblicos de envergadura nos llegaron sólo en traducciones. Por ejemplo, el Códice Sinaítico, encontrado en el monasterio de Santa Caterina en la Península de Sinaí, es del siglo IV EC, mucho más antiguo que los indicados, pero está escrito en griego. Es un texto de la Versión de los Setenta o Septuaginta (una traducción llevada a cabo por sabios judíos en Alejandría entre los siglos III-I AEC), de lo que los cristianos llaman el Antiguo Testamento, e incluye también el Nuevo Testamento.

El descubrimiento de los Rollos del Mar Muerto fue una noticia que sacudió al mundo. Por primera vez se habían encontrado testimonios de un libro bíblico -el libro de Isaías- muy anteriores a los conocidos. Cuando se realizó el anuncio el día 12 de abril de 1948 en Londres, se hizo mención a este libro y el impacto fue inmenso, aun en una época en que no se contaba con la actual tecnología de información. Pero no solamente se hallaron manuscritos bíblicos: entre los primeros siete Rollos se encontró el "Apócrifo del Génesis", un libro que comenta o relee el Génesis del Pentateuco de Moisés. El Apócrifo es una obra probablemente escrita en los siglos II- 
I AC que contiene un excepcional testimonio de exégesis bíblica, pues permite entender cómo los judíos de hace más de 2000 años leían el Génesis, y aporta una nueva visión a la interpretación de los textos bíblicos.

Hay otros cuatro libros entre estos primeros siete manuscritos que pertenecen a una categoría que los investigadores llaman "manuscritos sectarios". Son libros que deben haber pertenecido a un grupo que se consideraba los elegidos de Israel y que tenía una sociología, una teología y una forma de vida muy particular que los distinguía del resto de Israel. Uno de estos libros, escrito en hebreo y única copia conocida, es el "Comentario de Habacuc", un profeta de Israel que vivió hace 2.600 años, anterior a la destrucción del Primer Templo por los babilonios en el año 586 $\mathrm{AC}$, y que contiene una interpretación sectaria de cómo ciertos judíos leían al profeta en el siglo I AC durante la época romana.

Después del descubrimiento inicial, la investigación de los Rollos del Mar Muerto se relaciona con el gran tema del conflicto árabe-israelí. Al término de la Guerra de la Independencia de Israel, en 1948, la zona de Qumrán, así como todo el territorio de Judea y Samaria, quedó bajo el control jordano. En esos años, el famoso arqueólogo francés Roland de Vaux, director de la Escuela Francesa de Biblia y Arqueología (École Biblique), y a quien se le debe la Biblia de Jerusalén, asume un importante papel junto con el Profesor G. Harding, director de Antigüedades de Jordania. Ambos ubicaron la cueva de la cual se habían extraído los primeros siete Rollos, lo cual dio inicio a una carrera alocada entre arqueólogos y beduinos para encontrar más cuevas con rollos. La más rica de todas resultó ser la cueva $\mathrm{N}^{\circ} 4$, ubicada frente a las ruinas de Qumrán. Solo allí se hallaron 15.000 fragmentos de manuscritos de enorme importancia por la calidad, variedad y cantidad del hallazgo.

\section{La materialidad de los Rollos y la riqueza arqueológica de Qumrán}

Los Rollos del Mar Muerto están escritos en tres lenguas: 90 por ciento en hebreo, con distintas grafías; 8 por ciento en arameo y aproximadamente 1-2 por ciento en griego. El 80 por ciento está escrito sobre cuero animal y un 20 por ciento en papiro. Hay una excepción, y es un manuscrito en plancha de cobre -llamado el "Rollo de Cobre"- hallado en la cueva N³. Desenvolver este 
último Rollo demoró más de tres años y fue necesario cortarlo en lonjas para no dañarlo. El manuscrito original, escrito en un hebreo tardío del siglo I EC, está hoy en el Museo de Amán, Jordania. Menciona 64 sitios en el desierto de Judea en donde se escondieron tesoros de oro y plata.

Entre 1947 y 1956 se encontraron aproximadamente otros mil manuscritos, la mayoría muy fragmentados. Son entre 25 mil y 30 mil partes, de las cuales muy pocas están en buen estado de conservación. En la cueva $\mathrm{N}^{\circ} 11$ apareció uno de los manuscritos más importantes de la colección, llamado "El Rollo del Templo".

Roland de Vaux, quien continuó sus estudios y paralelamente excavaba las ruinas de Qumrán, formuló la idea de que habría existido algún tipo de relación entre los habitantes del lugar y los manuscritos hallados en las cercanías, ya que se encontraron tres tinteros, algo muy excepcional en el mundo antiguo. En Jerusalén, que fue por excelencia la capital de la literatura en la antigua Judea, solo se han encontrado dos tinteros. Sin embargo, eso no significa necesariamente que los Rollos hayan sido escritos en Qumrán mismo.

También se hallaron "mesas", pero no se sabe para qué fueron usadas. En el mundo antiguo no se escribía sobre tableros. Esta es una práctica que en Europa recién se conoció a finales del medioevo (por eso en las imágenes y pinturas de la época se ve a los evangelistas y a los escribas escribiendo sobre sus rodillas). Es posible que las mesas sirvieran para confeccionar los Rollos que eran más largos: por ejemplo, el "Rollo del Templo" debe haber tenido originalmente una longitud de unos nueve metros. Para su producción se utilizaron pieles de varios animales, que luego de ser escritas, fueron ordenadas y unidas mediante costura, tal como un rollo de la Torah. Y según parecería ser, se habrían requerido las supuestas "mesas" para llevar a cabo estas tareas.

Qumrán tiene un sistema de aguas que cruza los edificios de noroeste a sureste, con cisternas para acumular líquido. Algunas de estas cisternas tienen escalones, por lo que probablemente habrían servido con toda seguridad como piletas rituales -mikva'ot- para purificación. Qumrán es el segundo lugar de Israel con una semejante concentración de piletas rituales después de Jerusalén. 
Los miembros de la comunidad de Qumrán, cumpliendo un precepto básico, acostumbraban purificarse varias veces al día.

También se encuentran al sur de los edificios de Qumrán las ruinas de una habitación muy extensa, 22 metros de largo por 4,5 metros de ancho, y a su lado está ubicada una especie de despensa, en la que se hallaron unas 1.200 piezas de cerámica muy sencilla, sin decoración, usada para acopio de la vajilla. De Vaux llegó a la conclusión que esta gran habitación habría servido como refectorio para las comidas comunitarias, compartiendo los alimentos sentados en largas hileras de esteras.

Pero no solo tenemos edificios y rollos en Qumrán: también se hallaron platos de madera, peines (con piojos incluidos), lámparas de aceite, vasos de piedra y piezas de metal, dátiles y objetos de labranza, los que junto a otros artículos son parte del patrimonio de Qumrán, al lado de los famosos Rollos del Mar Muerto.

Un cementerio extraordinario fue descubierto con 1.200 tumbas, cada una señalada con un montículo de piedras, donde casi únicamente varones estaban enterrados. Solo en los sectores laterales del cementerio se encontraron unos pocos restos pertenecientes a mujeres y niños. A excepción de unas decenas de tumbas excavadas en los comienzos de la investigación, la mayoría de las mismas fueron descubiertas hace algunos años atrás gracias al uso de un sonar, ya que por la legislación vigente en Israel, está prohibido abrir tumbas.

\section{Las Revelaciones de los Manuscritosy los orígenes del Cristianismo.}

En el Museo Rockefeller de Jerusalén se llevó a cabo el estudio de los Rollos, los que son el mayor rompecabezas de la historia, porque no solo había que recomponer sino que además -y esto es aún más complejo- armar y descifrar. En muchos casos el desafío era reconstruir un libro que no sabíamos cómo había sido en su formato original.

Pero esta exposición se refiere a Juan Bautista, Pablo y Jesús, y puede parecer que este tema todavía no ha sido abordado; sin embargo, en realidad todo lo anterior se refiere a ellos, por cuanto los Rollos del Mar Muerto, aún cuando no mencionan a ninguno de estos grandes 
personajes, se han transformado en la clave para comprender los orígenes del cristianismo, y hoy es imposible estudiar el inicio de este movimiento religioso, que se inició como secta judía y se transformó en una religión universal que cambió la historia de gran parte de la humanidad, sin utilizar estos manuscritos.

¿Por qué los Rollos son tan importantes para entender la historia de la Iglesia si no mencionan a estos grandes personajes?

Para comprender este complejo tema es conveniente considerar lo siguiente:

Como sabemos, los Evangelios de Lucas y Mateo comienzan la historia sagrada con el relato de la infancia de Jesús, y solo después se habla del encuentro con Juan Bautista y de su bautismo en el río Jordán. Pero el Evangelio de Marcos, probablemente el más antiguo de los cuatro sinópticos, comienza hablando de Juan Bautista. La versión de Marcos empieza la presentación no con el Mesías sino con el profeta que lo anuncia. Esta es una estructura teológica que reconocemos en la literatura de la época del Segundo Templo y en los Rollos del Mar Muerto, que indica que la venida del Mesías habría de ser anunciada por un Profeta. El pensamiento de la religión cristiana refleja una estructura de la historia de la salvación al decir que tiene que venir un Profeta que anuncie la venida del Salvador.

\section{Juan Bautista}

Cuando la versión de Mateo cuenta la aparición de Juan, dice "por aquellos días se presenta Juan Bautista proclamando en el desierto de Judea 'conviértanse porque ha llegado el Reino de los Cielos '” (3, 1-2). Presenta a Juan como profeta escatológico que anuncia la inminencia del fin de la historia y por eso llama a la población un momento antes del Juicio Final.

Pero estamos hablando de un judío, y los judíos piensan en textos y justifican sus hechos, sus palabras, o sus pensamientos, en función de escrituras, entonces el relato evangélico continúa: "este es de quien habló el profeta Isaías cuando dice: 'Voz que clama en el desierto prepara el camino del Señor y ábranle un camino recto'" (3, 3). Es decir, en este caso el Evangelista, probablemente recogiendo una versión que incluso podría haber tenido origen en el propio Juan, 
utiliza un texto-prueba que es Isaías 40 versículo 3, con una lectura diferente a la lectura masorética influida por la versión de la Septuaginta, que bien es una interpretación posible. En la lectura del Evangelista hay una voz que clama en el desierto, y por supuesto que en esta exégesis, la voz que clama en el desierto es la de Juan, preparando el camino del Señor, la venida de Cristo.

Pero lo importante es que esta interpretación mesiánica utiliza el texto indicado de Isaías. Cabe preguntarse qué visos de historicidad tiene esta versión y tradición, y si su origen está en Juan Bautista. Al respecto, lo único que tenemos es el testimonio de los Evangelios y, por supuesto, no podemos utilizar como argumento de prueba el mismo texto que tenemos que probar.

El hombre de fe no necesita ningún argumento, porque las escrituras son reveladas según una tradición fiel que tiene origen divino. Pero desde la perspectiva de la crítica histórica, el hecho de que algo esté escrito en el Nuevo Testamento no le da valor más allá de saber que tiene un antiguo origen y, por lo tanto, no tenemos manera de comprobar la verosimilitud de esta tradición. Se podría sostener, por ejemplo, que es un argumento utilizado en estadios tardíos de la Iglesia a fin de justificar la acción de Juan.

En relación a este problema, y utilizando un método lógico, es que encontramos el aporte de los Rollos del Mar Muerto: en un texto clave encontrado en Qumrán en la cueva $\mathrm{N}^{\circ} 1$ llamado la "Regla de la Comunidad", del cual hay doce copias. Se lee en la columna 8 de la más completa de las copias, una referencia a los orígenes de esta comunidad que hace un miembro antiguo de ella: "Y cuándo éstos existan/como comunidad/ en Israel/según estas disposiciones/ se separarán de en medio de la residencia de los hombres de iniquidad [probablemente haciendo alusión a los habitantes de Jerusalén, con los cuales estaban en disputas], para marchar al desierto, para abrir allí el camino de Aquél" [es decir, Yahvé, Dios de Israel]. Aquí, el antiguo escriba qumranita indicaba un texto que cita: "Como está escrito: 'En el desierto preparad el camino de ****'" [en el original, en vez del Tetragrámaton o el nombre sagrado de Dios, aparecen cuatro puntos, a manera de subterfugio]. Se puede decir que el autor en este contexto, utilizó Isaías 40 versículo 3, el mismo que aparece en los Evangelios respecto de Juan. 
¿Esto prueba que Juan era miembro de la comunidad, o que acaso los qumranitas fueron protocristianos?

Mateo, cuando habla de Juan Bautista, dice que Juan llama a la población antes de la venida del Reino porque el Reino ya ha comenzado, y antes de que llegue el fin de la historia, el Juicio Final. El único recurso para salvarse es convertirse y volver al camino correcto de Dios. Pero luego agrega otra cosa: "confesaban sus pecados y Juan los bautizaba en las aguas del Jordán" $(3,5)$; es decir, se establecía una relación entre la acción de culto ritual del bautismo, que es una acción física, con un proceso espiritual de conversión del espíritu. La tradición neotestamentaria le atribuye a Juan que él veía una relación entre la acción ritual y el acto espiritual de la conversión.

Esto mismo aparece en otra versión, completamente independiente, de un judío del siglo I de nuestra era, el historiador Flavio Josefo, que no era contemporáneo de Juan ya que había nacido en la segunda mitad del siglo I EC. Aparentemente, Flavio Josefo conocía una versión muy fidedigna acerca de Juan, porque su nombre había tenido tanto realce que aún era conocido en su época. Hablando de Herodes Antipas, hijo de Herodes el Grande, el del asesinato de los Inocentes, escribió: "Herodes lo hizo matar a pesar de ser un hombre que predicaba la práctica de la virtud, incitando a vivir con justicia mutua, con piedad hacia Dios, y así poder recibir el bautismo" (Antigüedades Judías XVIII).

Era con esta condición que Dios consideraba agradable el bautismo. Se servían de él no para hacerse perdonar sus faltas, sino para purificar el cuerpo, con tal que previamente el alma hubiera sido purificada, es decir, Flavio Josefo explicaba que Juan creía que la condición previa a la purificación del cuerpo era la purificación del espíritu, que el ritual de la purificación del cuerpo no iba a entrar en vigencia si antes no se había producido una purificación del espíritu, lo que complementaba lo dicho por Mateo.

Este punto es clave en la teología de Juan. El bautismo como una metáfora de la conversión del espíritu y de la salvación inminente; la purificación del cuerpo es la expresión visual externa de lo que ha sucedido dentro del alma del creyente. 
Estos conceptos se ven confirmados con la Regla de la Comunidad de Qumrán, en el texto referido anteriormente, que dice respecto de la purificación del espíritu:

No quedará limpio por las expiaciones, ni será purificado por las aguas lustrales, ni será santificado por los mares o ríos, ni será purificado por toda el agua de las abluciones. Impuro, impuro será todos los días que rechace los preceptos de Dios, si dejarse instruir por la comunidad de su consejo.

Y en la última frase: "Y por la sumisión de su alma a todas las leyes de Dios es purificada su carne al ser rociada con aguas lustrales y ser santificada con las aguas de contrición" (III, 4-9).

En otras palabras, también la comunidad del Mar Muerto veía una relación estructurada entre el proceso de conversión espiritual y la purificación. Este elemento característico de la teología de Juan Bautista, lo encontramos también en los Rollos del Mar Muerto.

¿Significa esto que Juan podría haber sido miembro de la comunidad? Algunos investigadores afirman que es posible que Juan, en algún momento de su historia no conocida, haya tenido una vinculación, e incluso, que podría haber sido candidato a miembro de la comunidad. Hay varios elementos indicativos, como por ejemplo el área de predicación del Bautista.

Sobre esto, nada nos cuentan Juan o Marcos, pero sí Lucas, quien dice que Juan venía de descendencia sacerdotal: en el primer capítulo de Lucas, el Arcángel Gabriel anuncia al sacerdote Zacarías, cuando estaba sirviendo en el Templo, que habría de ser el padre de Juan Bautista. Y Lucas nos dice que Juan crece en el desierto. No entendemos por qué se fue al desierto, pero es interesante que Juan, de origen sacerdotal, no vive y no sirve en el Templo como su padre.

La tradición cristiana, por lo menos la de origen bizantino, coloca los orígenes de Juan en la aldea de Ain Karem, al sur de Jerusalén, pero elabora y desarrolla su identidad religiosa en el desierto, y Qumrán también está en el desierto. La tradición ubica su acción no muy lejos de allí, tanto la tradición que conocemos de la época bizantina, según la cual el lugar de bautismo de Juan es 
Qasr Al Yahud, a pocos kilómetros de Qumrán, u otra tradición cristiana que sitúa el lugar en Wadi Kharrar, en el lado oriental del Jordán, y también cercano a Qumrán.

En resumen, el área de acción de Juan no está lejos del lugar de los Rollos del Mar Muerto y de la comunidad de Qumrán, y su mensaje presenta claramente un carácter mesiánico y escatológico, el que también es un elemento central en la teología de los Rollos, pues la comunidad de Qumrán es fundamentalmente mesiánica y escatológica.

Aun cuando el bautismo es un vínculo central de relación y hay otros elementos fundamentales de la teología de Juan que pueden provenir de Qumrán, no se puede identificar a Juan Bautista con la comunidad del Mar Muerto; por el contrario, el Juan Bautista histórico que conocemos a través de los Evangelios se oponía radicalmente a la teología de Qumrán.

La teoría de la salvación de Qumrán, por ejemplo, refleja una comunidad exclusiva, cerrada, en la que solamente los elegidos por Dios, y por la presencia de Dios, podían formar parte de ella. Dios ha definido aún antes de la creación quienes habrían de formar parte de este movimiento. La comunidad de Qumrán creía firmemente en la predeterminación, un concepto extraño para la tradición bíblica pero que era parte central de la teoría qumranita. Es un concepto totalmente opuesto al que aparece en la teología de Juan Bautista, cuyo mensaje de salvación estaba abierto a todos los israelitas y no tenía nada de exclusivo.

Otra diferencia fundamental es que Juan Bautista no creó ninguna comunidad. La del Mar Muerto era una comunidad estructurada, jerárquica, muy exclusiva, cuyo proceso de admisión llevaba entre dos y tres años, y solo los elegidos por Dios podían pertenecer a ella. Juan, como se dijo, no creó una comunidad; su movimiento era carismático, donde él era el maestro reverenciado. De sus alumnos, el más selecto fue Jesús.

\section{Jesús}

Jesús el Galileo llega a Juan para ser bautizado. Lucas incluso supone una relación o vínculo familiar entre ellos, pero esta suposición no aparece en Marcos. 
Marcos no explica por qué Jesús llega donde Juan para ser bautizado, ni cómo sabe Jesús respecto de la existencia de Juan Bautista. Es un tema muy extenso para abordarlo en pocas líneas, no obstante se puede intentar acercarlo y graficarlo con un ejemplo.

Jesús es un gran maestro, y como gran maestro dice discursos. El gran discurso de Jesús es el Sermón de la Montaña en la versión de Mateo (caps. 5-7). En la de Lucas, la presentación paralela a Mateo, es el Sermón del Llano (cap. 6). Y como es de suponer, Jesús no habría repetido sus discursos, entonces probablemente el gran discurso que quedó en la memoria del pueblo habría sido el Sermón del Llano. Pero como Mateo habría querido presentar al gran Maestro, al Mesías, como el nuevo Moisés, entonces habría cambiado el lugar del sermón (del llano por la montaña) para acercar la figura de Jesús al mitológico Moisés.

Ese gran discurso, que probablemente fue dicho por el Jesús histórico y que impresionó tanto a sus seguidores, pertenece a la teología original de Jesús: la teología de amor de Cristo. Está en Mateo 5, cuando el Evangelista expresa "han oído que se dijo: 'Ama a tu prójimo y odia a tu enemigo', pero yo les digo: 'Amen a sus enemigos y oren por los que los persiguen'” (v. 43).

Este texto ocupa un papel central en la teología de Jesús, y por lo tanto también en el cristianismo. Es de enorme impacto porque comienza diciendo que Jesús va a presentar algo que supone que todos saben: "ama a tu prójimo", una cita bíblica expresa del Levítico 19, 18. La Torah habla de amar al prójimo como a ti mismo, y sin duda en este caso Jesús aludía a un texto conocido por la tradición. Pero en la misma frase agregaba “....y odiarás a tu enemigo”, lo cual ha significado un verdadero desafío para los biblistas a lo largo de los siglos.

¿A qué textos hacía referencia Jesús en esa última parte? No es un texto que nosotros conozcamos pero la gente de la época sí lo conocía, pues él expresa "han oído que se dijo". Y no hay duda de que la segunda parte de la proposición, cuando afirmaba "pero yo les digo", formaba parte de la tesis de Jesús, que hablaba con autoridad, desde su posición y su conciencia de ser portador de un nuevo mensaje. 
Jesús presenta una nueva visión de la realidad, una novedosa versión radical de la Salvación y, a partir de este mensaje radical y de su autoconvencimiento de que posee un nuevo mensaje, es que trae "la buena nueva".

"Pues yo les digo", es una frase muy poco común en las fuentes judías, ya que es Dios quien utiliza el Yo, a excepción de Hillel el Sabio, que es anterior a Jesús, por lo cual es posible que Jesús haya sido influído por la Escuela de Hillel.

"Amen a sus enemigos", es el nuevo mensaje, distinto a las tradiciones anteriores; es decir, la tesis de Jesús necesita la frase anterior. Y es precisamente aquí donde los Rollos del Mar Muerto aportan nuevos datos que nos obligan a leer de manera diferente la literatura conocida.

En la Regla de la Comunidad, el texto es parte del ritual de alianza de los nuevos miembros, cuando eran incorporados plenamente. El ritual enunciaba los principios ideológicos de la comunidad, que dicen:

Para admitir en la alianza de la gracia a todos los que se ofrecen como voluntarios a practicar los preceptos de Dios, a fin de que se unan en el concepto de Dios y marchen perfectamente en su presencia, y de acuerdo con todas las cosas reveladas sobre los tiempos fijados de sus testimonios, para amar a todos los hijos de la luz, cada uno según su lote en el plan de Dios, y odiar a todos los hijos de las tinieblas, cada uno según su culpa en la venganza de Dios (I, 6-11).

Este grupo de clara orientación dualista, establecía una división clara y total entre el bien y el mal, la pureza y la impureza. Los miembros de la comunidad se autodenominaban "Hijos de la Luz", los elegidos por Dios, y sus enemigos, judíos o no, por igual son "Hijos de las Tinieblas". En esta visión dualista del grupo, la ordenanza bíblica entendida desde una perspectiva sectaria era amar a los miembros de la comunidad, a los "Hijos de la Luz", y por lo tanto concluía que entonces había que odiar a todos los que no pertenecían a la comunidad. 
El descubrimiento de la literatura con los principios ideológicos de la comunidad del Mar Muerto, iluminó como una nueva mañana el pasaje referido de Jesús "han oído que se dijo: 'Ama a tu prójimo y odia a tu enemigo'”. Nos demuestra que él habría estado haciendo una referencia a grupos como los de Qumrán.

No podemos decir específicamente que Jesús haya estado hablando de la comunidad de Qumrán y es posible que mañana encontremos nuevas cuevas que muestren algo diferente- sin embargo, Jesús estaba haciendo referencia a una teología como la de Qumrán, en la cual se prescribía odiar a los enemigos. Claramente Jesús se oponía a tal teología, de manera que no se puede afirmar que Jesús habría sido miembro de esa comunidad, como aparece a veces en alguna literatura carente de seriedad. El Jesús histórico se opuso firmemente a una teología como la qumranita.

Ahora podemos entender que el tema del amor entraba en un contexto donde grupos polemizaban acerca de qué actitud asumir hacia personas que no eran parte del movimiento: ¿integrarlos, alejarlos, amarlos, odiarlos?

Los Rollos del Mar Muerto no hacen mención expresa de Jesús pero nos permiten recontextualizar el mensaje neotestamentario, con un nuevo marco conceptual para entender la tradición transmitida por la Iglesia.

Después del descubrimiento de los Rollos ya no es posible afirmar que la frase primera de Jesús podría haber sido elaborada por algún cristiano que haya vivido años después de los hechos, a pesar de nuestra presunción occidental que lleva muchas veces a desprestigiar el concepto de tradición, puesto que estamos en un mundo en el que se puede mentir, se puede decir de todo y no se tiene respeto a la palabra.

Los Rollos del Mar Muerto alumbran cuestiones centrales de cómo entendemos nuestras tradiciones. Si bien no pueden probar lo que Jesús haya dicho, sí verifican que los dichos que la tradición atribuye a Jesús se adecúan a los grandes problemas ideológicos y religiosos del judaísmo del Segundo Templo, y que esta tradición tiene sentido en el contexto de aquella época. 


\section{Pablo de Tarso}

En la segunda carta de Pablo de Tarso a los Corintios, este gran pensador escribe:

No os unáis en un mismo yugo con los que no creen. Porque ¿qué tienen en común la justicia y la injusticia? ¿O qué unión puede haber entre la luz y la oscuridad? No puede haber armonía entre Cristo y Belial, y entre un creyente y un incrédulo. No puede haber nada en común entre el Templo de Dios y los ídolos. Porque nosotros somos el templo de Dios viviente, como Él mismo dijo: Viviré y andaré entre ellos; yo seré su Dios, y ellos serán mi Pueblo (6, 14-16).

Es difícil entender la teología de Pablo pero tenemos sus escritos que son excepcionales. Las Cartas Paulinas representan la etapa más antigua de los textos neo-testamentarios, y son los escritos más antiguos de la Iglesia.

Pablo enviaba cartas a sus comunidades, como parte de su política eclesiástica. Estas epístolas están incluidas en el Canon en lengua griega. Educado en el mundo greco-romano, también se autodefinía como un judío fariseo que utilizaba una terminología dual -luz/oscuridad, Cristo/Belial (es decir, Satán)- y nuevamente los Rollos del Mar Muerto son claves para entender su lenguaje teológico.

Uno de los textos de Qumrán contiene un primer intento de presentar la teología de manera sistemática. En él se dice:

Él creó, para dominar el mundo, violentos espíritus para quemarse con ellos hasta el tiempo de su visita... los simplistas de la verdad y la falsedad, del manantial de la luz provienen las afirmaciones de la verdady la fuente de tinieblas que hacen falsedad en manos del príncipe de la luz está el dominio sobre todos los hijos de la justicia y ellos marchan en caminos de luz 
enviados en manos del ángel de luz está todo el dominio sobre los hijos de las tinieblas y ellos marchan por el camino de la falsedad. (III, 17-21)

Es decir, algo que caracterizaba el pensamiento y la teología qumranita, era el uso de la antítesis luz/oscuridad, que es exactamente lo que encontramos en el pasaje paulino referido. Por eso, incluso se ha llegado a cuestionar si este pasaje de Corintios 2 habría sido originalmente compuesto por el mismo Pablo, o en su defecto, habría sido un texto qumranita interpolado en la carta paulina.

Las epístolas de Pablo hacen recordar muchos elementos de Qumrán. Uno de ellos es el nombre Belial, típico de Qumrán y no recurrente en los escritos neotestamentarios, lo que permite pensar que esta parte de Corintios 2 tenga su origen en fuentes literarias que conocemos de Qumrán.

Otro argumento convincente lo encontramos cuando Pablo dice "no puede haber nada en común entre el templo de Dios y los ídolos, porque nosotros somos el templo de Dios viviente". Este concepto, con el que Pablo hace referencia a la comunidad cristiana, a la Iglesia como templo espiritual, no se encuentra testimoniado en ningún otro escrito a excepción de los Rollos del Mar Muerto.

Cuando los autores anónimos de Qumrán describían a su comunidad, lo hacían del siguiente modo:

Cuando estas cosas existan en Israel, el consejo de la comunidad será establecido en verdad como una plantación eterna, una casa santa para Israel y el fundamento del santo de los santos para Aarón, testigos verdaderos para el juicio y escogidos de la voluntad (de Dios) para expiar por la tierra y para devolver a los impios su retribución (VIII, 4-7).

Así, el autor qumranita utilizaba un lenguaje litúrgico que tenía como origen el Templo; hablaba de la comunidad como "el santo de los santos", como un lugar que sirve para expiar la tierra, y la expresión era central en el Templo en Jerusalén. Es la primera vez que conocemos en toda la 
literatura judía de Israel, que se entiende a la comunidad como un templo espiritual, y ese mismo concepto lo encontraremos después en los escritos paulinos.

Eso significa que en Pablo podemos encontrar terminología y conceptos teológicos que muestran una clara relación con el pensamiento qumranita. Tan claro es, que uno de los grandes pensadores e investigadores de los Rollos del Mar Muerto, el extinto profesor David Fluser, publicó un libro con un artículo clásico donde hablaba de la literatura pre-paulina. Cuando hacía referencia a los Rollos, los textos parecían haber sido escritos por Pablo. Por ejemplo, los conceptos de gracia, de predeterminación, de pecado, que son centrales en el pensamiento y en los escritos paulinos pero no en el pensamiento de Jesús, están en los Rollos del Mar Muerto.

Aquí apreciamos elementos que demuestran algún tipo de relación profunda con lo que conocemos en la literatura y pensamiento qumranita. ¿Cómo llegó esto a Pablo? No lo sabemos, pero el pensamiento paulino refleja un contacto no tangencial sino esencial. La tensión paulina refleja corriente de pensamiento que reconocemos en los Rollos del Mar Muerto.

Otro texto de Qumrán, conocido como el 4Q174 o 4QFlorilegium, dice: "Y ordenó construir para él un templo de hombre" (frag. 1-3 col. I, 6). Es la única vez, en todos los Rollos del Mar Muerto, que aparece la expresión mikdaš adam que habla de la comunidad como de un "templo de hombres". Es el mismo concepto que encontramos en Pablo: "somos el templo del Dios viviente".

Lo señalado no puede ser una casualidad; es una terminología técnica que reflejaría una relación visceral entre los escritos de los Rollos del Mar Muerto y los escritos paulinos.

\section{El Mensaje Espiritual de los Rollos del Mar Muerto}

Los Rollos representan un enorme tesoro intelectual y espiritual, y un aporte para entender las figuras de Juan Bautista, Jesús y Pablo. Desde el punto de vista de la crítica, de la historia y de la teología tienen una importancia crucial. Aún hoy, en el siglo XXI, en esta era de la tecnología y de la vida virtual, estos escritos antiguos tienen un mensaje para nosotros. 
El Santuario del Libro en Jerusalén, es un edificio excepcional. En la tercera sala están los Rollos del Mar Muerto, todos los originales, salvo el Rollo de Isaías que, para poder preservarlo a las futuras generaciones, se exhibe en facsímil. Este manuscrito, junto con otros cuatro, fue publicado el 26 de septiembre de 2012 en Google, y han sido abiertos para todos. Son copias de gran calidad visual (1,200 megapixels), algo inimaginable hace pocos años, y sin duda además para los hombres de Qumrán.

Hoy podemos acceder a sus contenidos y significantes, lo que nos lleva a cuestionar ¿de qué manera estos Rollos pueden contribuir al mejoramiento de la calidad de vida? En los días que vivimos hoy, la calidad material de vida ha alcanzado un nivel como nunca antes: viajamos muy rápido, leemos más rápido, podemos acumular una biblioteca en un celular; en fin, son logros que parecen de ciencia ficción para los mayores de 50 años. Entonces ¿qué nos pueden aportar unos escritos de hace 2.000 años atrás?

Pienso que la frase de Isaías tiene aún plena vigencia para nosotros en nuestros días:

Lo que dijo la voz acerca de Judá y Jerusalén hasta donde será terminando los tiempos quedará confirmado el monte donde se halla la casa de Yahvé, como cabeza de los montes. Y correrán a él de todas las naciones y verán y vendrán nuevos pueblos y naciones diciendo: 'Venid al monte de Yahvé, a la casa de Dios de Jacob, que Él nos enseñará sus caminos y caminaremos por su senda. Porque de Sión saldrá la Ley, de Jerusalén la palabra de Dios. Él juzgará entre las naciones y reprenderá a los pueblos. Ellos convertirán sus espadas en arados y sus lanzas en hoces. Y no alzará espada nación contra nación ni se adiestrarán más para la guerra' (2, 1-4)

El gran profeta de Israel vivió hace 2.800 años y en un mundo donde adoramos el dinero, la velocidad, la cantidad, donde todo se ha transformado en digital y cibernético, nos hemos olvidado del verdadero lugar de la palabra. Los Rollos del Mar Muerto son palabras, lo que queda y quedará no son estos manuscritos de cuero sino las palabras, el espíritu hecho palabra, y esas 
palabras están inscritas en rollos que son una tecnología de otra época, cómo sucederá en pocos años cuando nuestros hijos considerarán nuestra tecnología actual como algo arqueológico. Pero los Rollos del Mar Muerto, que hoy forman parte de la historia de la espiritualidad de la humanidad, han perpetuado las palabras de Isaías, ese profeta con un mensaje de paz universal. Que hoy, desde Jerusalén, he traído para ustedes, y que no es otro que un mensaje de PAZ, Shalom.

\section{Bibliografía}

Josefo, F. (2002). Antigüedades judías. Madrid: Akal Clásica, 2 vols

Roitman, A. (2000). Sectarios de Qumrán. Vida cotidiana de lo esenios. Martínez Roca.

Roitman, A. (1997). A Day at Qumran . The Israel Museum.

Roitman, A. (2010). Biblia, exégesis y religión. Una lectura crítico-histórica del judaísmo. Verbo Divino, 2010.

Rollos del Mar Muerto. En línea: http://dss.collections.imj.org.il/ Sitio oficial de los Rollos del Mar muerto. Revisado en Noviembre de 2013. 